\title{
The evolution of a national research plan for computers in education in The Netherlands
}

\author{
J. Moonen \& B. Collis, Department of Education, University of Twente \\ K. Koster, Department of Education, University of Groningen
}

\begin{abstract}
This paper describes the evolution of a national research plan for computers and education in The Netherlands. This approach was initiated in 1983 and includes two phases: one from 1984 until 1988 and one from 1989 until 1992. The paper describes the research plans for the second phase, based upon the experiences of the first, and draws some general conclusions about the development of national research plans for computers in education.
\end{abstract}

Keywords: National research plans; Computers in education; Implementation issues; Survey results.

\section{Introduction}

The March 1989 edition of the Journal of Computer Assisted Learning 5(1) was devoted to an initial description of research projects for computers in education in the UK that are being organized and coordinated at the national level under the Information Technology in Education Research Programme, 1988-1993. There is also information about the process that was undertaken, through the support of the Economic and Social Research Council, to develop and select the research themes that form the subsequent focus of the 1988-1993 Programme. One of the overall aims of this Programme is 'to promote the development of a critical mass' with regard to previously fragmented and 'somewhat scattered' research efforts (Lewis, 1989). There are many parallels between the UK experience and the national research initiative for computers in education in The Netherlands. The Dutch activity was initiated in 1983 and its first phase has recently been completed (Van der Klauw, 1988). Lessons that have been learned from the first phase of research activity plus new perspectives reflecting the broader national and international experience with computers in education have contributed to the development of priorities for research activities for the 1989-1992 period. In the spirit of contributing to a 'critical mass' of experience relative 
to research in computers in education, we shall describe the Dutch experience in more detail.

\section{Background information about The Netherlands situation}

\section{Organization of educational research}

Educational research in The Netherlands is executed by universities after being initiated either by them or by the Institute for Educational Research (SVO). This Institute does not perform research itself but invites universities to apply for research projects. A formal evaluation and decision procedure is followed after applications are sent in to the SVO. In order to create research frameworks for different aspects of education, SVO regularly gives assignments for the execution of so-called 'problem exploration studies'. Such studies are focused toward a certain educational area and result in inventories of crucial research approaches and research questions.

\section{National support for computers in education}

In 1984 the Dutch government launched a 5-year Informatics Stimulation Plan, the 'INSP'. The major emphasis of the plan was to create a momentum for the introduction of computers in business, research and education. A specific part of the plan focused on stimulation of the area of computers and education and had a budget of approximately 160 million US \$. Projects were set up to support the introduction of computers in different educational sectors: primary; secondary (general and vocational); and special education. Special programs were initiated to start the development of a national and regional infrastructure and methodology for courseware development. Much emphasis was put on teacher training (in-service and pre-service). Only a very small part $(2.5 \%)$ of the plan, however, was related to research.

The INSP ended in December 1988 and has been followed by another 5-year plan: the PRINT-project. The major emphasis of this new project is to continue the efforts started during the INSP, and to specifically focus on the implementation of computers into education. The budget for this plan is even higher than the INSP budget (250 million US \$). However, none of the PRINT budget is allocated for research. Research, which is to be financed separately by the SVO, equals only $1.3 \%$ of the amount of the PRINT budget.

\section{Research on computers in education in $1984-1988$}

The first 'problem exploration study'

Although individual research projects on computers in education had started in The Netherlands in the latter part of the 1960s, the SVO initiated 
the first systematic problem exploration study in 1983-1984. A broadly focussed study was completed (Dirkzwager et al., 1984) and a national conference of researchers was conducted at the end of 1984 to discuss the recommendations of the study. However, because of the broad focus of the study and the awareness that the entire area of computers in education was still at the exploratory stage, there was not a sense of agreement on research focuses after the conference was finished. As a result, a great diversity of research projects were proposed and funded following the first problem exploration study.

Overview of research during $1985-1988$

During the $1985-1988$ period, therefore, a great variety of unconnected, nationally funded research went on in the area of computers in education. * Eighteen projects were funded by the SVO under its official program line (supposedly grounded in the first problem exploration study), 24 projects were done in association with the INSP, and three other projects (each initiated by a team of university researchers) were also funded nationally. As is not surprising given the lack of specific research focuses in either the SVO or INSP contexts, an analysis of these research efforts shows little coherence among them. However four clusters of types of research emerge: $†$

- Feasibility studies, surveys and evaluation research ( 20 projects).

- Research and development of educational software (8 projects).

- Theoretical research (14 projects).

- The 'Experimental Stations' project.

The 'Experimental Stations' project deserves special comment.

\section{The 'Experimental Stations' concept}

During the INSP period (1984-1988) the idea gradually grew that a number of research questions about computers in education could not be answered properly following traditional research approaches. Moreover, it was felt to be necessary to have opportunities during the execution of a research project to be able to adapt circumstances to changing educational opinions and to new developments in the field of information technology. As a result, these ideas led to the creation of so-called 'Proefstations' - 'Experimental stations'. An experimental station is a cooperative effort in which some schools work closely together with a research group.

The type of research that was seen as appropriate to be conducted in such a new context related to the impact of large-scale computer usage within a school environment on the organization of the school, the management of the school, the attitudes and tasks of the teachers, the influence on the curriculum and the performance and motivation of students.

To maximalize the chance that significant changes should be able to

*For a list, in English, of the titles of these projects, see the appendix

†Because of double counting, the totals do not equal the numbers given in the paragraph above 
occur, the participating schools were equipped with extra resources (hardware, courseware, and personnel facilities). It is important to notice, that the 'experimental' schools in this context are not meant to be 'model' schools. It is clear that the extra financial means available to equip these schools is not going to be generally available on a large-scale basis. The experimental stations therefore have to be interpreted as a kind of 'experimental garden' in which new seeds are tried out. In this context, the 'soil' of this experimental garden should be the best, considering circumstances, that is available. If the approach is fruitful, one has to identify the significant variables that can transfer to implementation on a broader scale within more restricted circumstances.

The crucial questions for the experimental station researchers are: if they will be able to come up with significant results; and, even more difficult, if they will be able to identify the minimum level of facilities needed to keep the same results; and most difficult, if their results can be translated into policy that is executable on a broad scale.

To prepare for the experimental stations project, feasibility studies were conducted in 1986. As a result of these studies, two experimental stations were set up, both in the general secondary school sector (one connecting one school in the western part of The Netherlands with research groups at the University of Utrecht and the Free University of Amsterdam, and the other connecting two schools in Enschede with a research group of the University of Twente). During 1987 and 1988 a pilot project was conducted to investigate the circumstances under which a 4-year project could be initiated and to work out project plans for it which could be implemented during the period $1989-1992$.

Conclusions from the overall $1985-1988$ research activities

Although a 'scientific' effort to integrate the results of the overall 1985 - 1988 research projects was not undertaken, an examination of their contents can yield some general conclusions from the research during this period (Moonen et al., 1989).

An examination of the feasibility studies and surveys suggests that:

(1) The introduction of the use of computers in schools takes much more time than was expected. An 'incubation' time of 2 years appears to be perceived as a minimum time.

(2) One does not get the impression that surveys have a crucial influence on the formulation of a governmental policy. When there is no direct connection between surveys and follow-up studies, especially policyoriented activities, one can question the value of the surveys, especially because they lose their topicality rapidly.

(3) Although there was considerable experience in higher education about how to use computers in education, the activities of the INSP were not related to the research results and experience of the higher education 
sector. This lack of cooperation was caused by the fact that university education was excluded from the INSP.

In general the following conclusions can be formulated about the software development research:

(1) The complexity of writing computer-aided learning programs beyond the drill-and-practice mode was highly underestimated.

(2) There was no integration of software development projects aimed at software for direct infusion into schools and 'development/research' projects in which software was developed in the context of specific theoretical research questions. However, both types of software development projects should complement each other.

(3) There was no adequate software development infrastructure in The Netherlands; too many research institutes want to be involved in this area but they lack the hardware, the software and the professional experience to work in an efficient way. Creating a limited number of high-quality software development units seems to be desirable.

There are also some overall conclusions about the theoretical studies:

(1) The theoretical research projects had no specific interrelationship with each other. However, a central theme can be seen in many of those projects. This theme is related to the development of effective feedback procedures during the interaction of students with a computer program, including the construction of intelligent tutoring systems and computer coaches. It appears that no significant progress can be reported from the theoretical research studies, leading to the following general conclusion:

(2) Because of the complexity of work in the area of effective feedback and tutoring systems, it is highly desirable that cooperation among researchers in the application of artificial intelligence techniques to computer-based education be better organized, certainly in The Netherlands, and also on an international scale.

General conclusion from the overall 1985-1988 research activity

A final, overall conclusion can be made from the results of this period:

(1) The next national research plan for computers in education should be developed in a clearly stated and specific context, in order to avoid 'fundamental' discussions which can result in confusion and endless compromizes and to promote better consolidation of the research output.

\section{The second problem exploration study for computers in education}

\section{Commissioning of the second problem exploration study}

The SVO commissioned a second problem exploration study to support a new research line for computers in education for 1989-1992. The letter of 
assignment for this study, sent in the beginning of 1988 to Professors $J$. Moonen of the University of Twente and K. Koster of the University of Groningen, set the following expectation:

'After considerable efforts done in this area (computers in education) by the government, especially in relation to hardware provisions, teacher training and courseware development, there is a general feeling that the time has come to get better and more precise insight in the effects of the invested money. Therefore, a new research agenda has to be established whose results give concrete indications about the effects of computers on education, and through which it will become possible to evaluate the investment of the past'.

In addition, the letter of assignment suggested that $40 \%$ of the available budget for research on computers and education for the period 1989-1992 could be spent on the experimental stations project. The problem exploration study had to discuss this suggestion and develop recommendations in that respect.

To approach the overall problem exploration study task, new surveys were commissioned, as was a sub-study. The purpose of the sub-study was to develop a timely and productive theoretical framework from which research recommendations could evolve.

\section{'State-of-affairs' survey in anticipation of the second research period}

During 1988 new surveys were therefore conducted in the basic education, secondary education, and vocational educational sectors in order to identify productive subsequent research areas based on questions of strongest current interest in the field. From these surveys, the major issues identified by teachers related to their perceived lack of appropriate support and training relative to computers in schools, and to the lack of effective strategies for information dissemination and transfer about current aspects of computers in education. In addition teachers wished to be better able to evaluate courseware themselves and to get concrete suggestions about how to integrate computer usage in the curriculum.

\section{Setting a general framework for the second problem exploration study}

From the theoretical sub-study which was commissioned, a critical central decision was made about the orientation of the second problem exploration study. This was that the conceptual framework of the study would not focus directly on learner performance. This was because of two major sets of reasons that are felt to make systematic assessment of learner outcomes, presumably as caused or mediated by computer applications within the learning experience, limited in effectiveness at this time.

One of these reasons is the limited understanding of the complicated, interrelated network of factors that influence any eventual impact of computer use on a learner's performance (Collis, 1988). These factors include teacher, resource-related, and instructional-organization aspects. These 
three major sets of influences are highly multifaceted and together form parameters within which all learning impact occurs. It was felt that a major reason why so much current research activity attempting to illuminate learner outcomes as mediated by computers is inconsistent or unconvincing is that this larger network is treated as if it were a homogenous constant. Before we can fairly comment on the impact of computers on the learner we must know more about the influence of this surrounding network, at least to the extent of being better able to systematically elaborate its most salient characteristics relative to the subsequent impact of computer experiences.

A second reason for postponing a direct focus on learner outcomes for the second phase of SVO-supported research activity is the problem of measurement. Reliable and valid assessment criteria for the impact of computers in education and instrumentation to measure the extent of change relative to those criteria are not well established. The UK research framework also recognizes this problem (Lewis, 1989). Criteria relating to cost-benefit analyses would be particularly useful, yet no common procedure exists to determine a basal framework for cost-benefit quantification, not only of student performance but also of teacher support activities, and of organizational variations. In place therefore of research directly focused on learner outcomes, the theoretical sub-study recommended research focuses on better understanding of certain critical implementation aspects and on measurement strategies. These implementation aspects include teacher support and training, software evaluation from the teacher's perspective, and issues related to the social and physical organization of school computer use. An English summary of this implementation-oriented theoretical framework is available (Moonen et al., 1989).

\section{Selecting a recommended research theme for 1989-1992}

Following the surveys and the theoretical sub-study, and influenced also by practical realities such as budget constraints, a preliminary set of recommended research themes was elaborated (Koster \& Moonen, 1988) and presented to The Netherlands educational research community prior to a conference in November 1988. The recommended research priorities were:

(1) Courseware evaluation by teachers: procedures and criteria.

(2) Research toward the effects of alternative approaches for the inservice training of teachers; for example, research into the possibilities of teachers using computers at home for the preparation of their lessons and for better use of feedback about student performance generated by CMI software, or toward the possibilities of using telecommunications in the context of inservice training.

(3) Research about what kind of computer-aided learning is felt to be useful in vocational education. Should professional packages be used and integrated in regular curricula, for instance, using embedded training techniques? What kind of computer applications should get priority in vocational education? 
(4) Research about cooperative learning with computers.

(5) Methodological studies directed toward the eventual effect evaluation of the influence of computers, particularly on higher order cognitive skills.

(6) Research toward the applicability of artificial intelligence techniques to be used during the production of courseware.

(7) Continued but better consolidated work in the development of interactive coaches.

In addition, strong support for the experimental stations was also recommended. The main arguments for the continual emphasis on the experimental stations projects was that the general tendencies of the research to be conducted in the experimental station projects were in harmony with the research themes suggested in the other part of the National Research Plan (as indicated by Recommendations 1 to 7 above) and the continued conviction that certain relevant research questions could only be effectively tackled in an environment such as that created by the experimental station approach. It is interesting to note that Recommendations 4 and 5 of the list of recommended research priorities directly parallel two of the four streams being implemented in the UK Information Technology in Education Research Programme for 1988 - 1993 .

\section{Toward the future development of computer-related educational research for 1989 - 1992}

After a lively discussion at the November 1988 research conference, the orientation of the second problem exploration study and its recommendations were generally accepted. Further work was commissioned to be done by Moonen \& Koster in early 1989 to expand upon the research theme recommendations and to do so in collaboration with the research activity getting underway in the PRINT project (the successor to the INSP). Tenders for the first two of the recommended themes - software evaluation and teacher support - have gone out and the research contract for the software evaluation has been awarded to a team at the University of Twente (Project Leader, Dr G. Carleer; Project Supervisors, Professor Dr Tj. Plomp \& Dr B. Collis). Proposal specifications are being developed for the remaining research lines and will be available for competition by mid 1989, In addition, the experimental station research is in full operation.

\section{Reflections on the Dutch experience}

Perhaps the most noteworthy conclusion about the Dutch computers in education research experience until now is that Dutch researchers agreed to spend a great percentage of money $(40 \%$ of the available research budget given to the experimental stations project as well as four out of seven of the recommended research projects) on research associated with 'implementation' of computers in education. The agreement on four out of 
seven research priorities emphasizing implementation rather than basic research is even more remarkable when it is realized that this agreement came after the sizable commitment to the experimental stations had already been made. Apparently there is a general conviction that this kind of research is what we need NOW.

In particular, the experimental stations project seems to be accepted as a new paradigm in which to conduct educational research. Dutch researchers seem to be ready to go along such new paths. At the same time, one can conclude that in The Netherlands there is almost no opportunity anymore to get funding for research proposals that do not fit into wellprepared and well-discussed general research directions. The hope is that better synthesis and dissemination of results can come from this strategy and that Dutch research can then make a substantial contribution to the much-needed 'critical mass' of research activity which is also an aim of the UK Information Technology in Education Research Programme.

\section{References}

Collis, B. (1988) Manipulating critical variables: a framework for improving the impact of computers in the school environment. Paper presented at EURIT'88, Lausanne, Switzerland.

Dirkzwager, A., Kommers, P., Min, R. \& Plomp, Tj. (1984) Problem exploration study for the implementation of information technology in education. SVO, The Hague, The Netherlands.

Koster, K.B., \& Moonen, J. (1988) Information Technology and Education: Proposals for a Research Programme. SVO, the Hague, The Netherlands.

Lewis, R. (1989) Information Technology in Education Research Programme 1988 - 1993. Journal of Computer Assisted Learning, 5(2), 11.

Moonen, J., Collis, B., \& Koster, K.B. (1989) The evolution of a national research plan for computers in education in The Netherlands. Report presented at the annual meeting of the International Association of Computing in Education, San Francisco.

Van der Klauw, C.F. (1988) Research on the application of the computer in education. SVO, The Hague, The Netherlands.

\section{Appendix}

Nationally Funded Research, Computers in Education, in The Netherlands During the Period 1985 - 1988

The number(s) after each study indicates the code under which the research is known at the SVO. Further information about a particular study can be obtained from the SVO, Sweelinckplei 14, 2517 GK DEN HAAG, The Netherlands.

Feasibility studies, surveys and evaluation research

- Preliminary studies for the so-called 'Experimental Stations' $(6117,6118,7112$, 7109). 
- Description and evaluation of the '100-schools project' $(1152,4204)$.

- Computers in education - the IEA study (6106/7127).

- Modulating technical informatics in middle vocational education (7126).

- Possibilities and consequences of large-scale computer use (7111).

- Practical implications in the area of vocational education (5539).

- Basic skills in vocational education (4196).

- Needs and capacity for inservice training in general and vocational secondary education (4201).

- Support and evaluation of inservice training in information technology for primary school teachers (4198).

- The use of computers in education with highly talented students (6100).

- Computer-aided instruction for children with learning disabilities (4192).

- Effects on long-term LOGO instruction in primary education (7005).

- Different didactical approaches in CAI (6632).

Research and development of educational software

- A computer-aided orthodidactical program for initial reading (4131).

- Infusion of computers in existing curricula (1100).

- Development of a test-item banking system (4266) $2 x$.

- Computer-aided foreign language teaching $(7108,6101)$.

- Computer-aided arithmetic education for children with learning disabilities (1025).

- Conditions for courseware use (1086).

\section{Theoretical research}

- Development of a computer coach for thermodynamics (1039).

- Knowledge technology in computer-aided grammar and orthography education $(5620,5630)$.

- Structural analysis of dialogues in relation to interactive problem solving (4237, 7003).

- Graphical support in relation to problem solving (6617).

- Training of the approach and the solution of arithmetic exercises following a general model (6618).

- 'Buggy' rules (7101).

- The relation between computer-supported laboratories, students' characteristics and cognitive learning effects (7015).

- Feedback processes in computer-aided orthography education (7345).

- Preliminary study in relation to multiple evaluation as a test method (7345).

- Stimulation of problem solving by using intelligent tutors (7110).

- Research toward computer-aided instruction in mechanical engineering (7107).

- Computer-aided learning for verbal information (7103). 